INORG. NUCL. CHEM. LetTers Vol. 8, pp. 147-152, 1972. Pergamon Press. Printed in Great Britain.

\title{
SYNTHESIS AND CHARACTERIZATION OF SOME CIS COMPLEXES \\ OF THE TYPE $\left[\mathrm{Cr}(\mathrm{pn}) 2_{2}^{\mathrm{AX}}\right]^{\mathrm{n}+}$ *
}

J. A. Mclean, Jr, and N. A. Maes

Department of Chemistry, University of Detrott, Detroft, Mich1gan 48221

\section{(Received 1 November 1971 )}

Recently we reported the synthesis of the trans-dibromobis(propylenediamine) chromium(III) cation (1). Other trans complexes of this type which are known are the difluoro (2) and dichloro (3). In the case of the corresponding cis complexes only the difluoro (4) has been fully characterized in the solid state.

In the course of our studies of the acid and base hydrolysis of the trans dibromo complex, it became necessary to independenty synthesize the cis bromoaqo species as a possible reaction intermediate. The search for a synthetic route to this cation has also led to the successful synthesis and characterization of cis-[Cr(pn) $\left.{ }_{2} \mathrm{Cl}_{2}\right] \mathrm{Cl}$ and $c i s-\left[\mathrm{Cr}(\mathrm{pn}) \mathrm{Brr}_{2}\right] \mathrm{Br}$ in the solid state. The large solubilities of these salts preclude their isolation from aqueous solution as solid samples of reasonable purity. We have developed procedures which overcame these difficulties.

\section{Experimental}

cis-[Cr(pn) $\left.{ }_{2} \mathrm{CI}_{2}\right] \mathrm{Cl}$. The violet chlorodimethylsulfoxidechromium(III) complex was prepared according to the method of

\footnotetext{
*Abbreviations used: en = ethylenediamine, pn = propylenediamine $=1,2-d i a m i n o p r o p a n e$.
} 
Pedersen (5) and used as the starting material. Chromium(III) chloride hexahydrate $(40 \mathrm{~g}, 0.15 \mathrm{~mole})$ was dissolved in $80 \mathrm{ml}$ of dimethyl sulfoxide and heated to $\sim 188^{\circ}$ to remove the water. The solution was allowed to cool to $110^{\circ}$ and stirred while dry propylenediamine $(0.30$ mole) was added dropwise. The reaction mixture was then heated in an o1 1 bath at $150^{\circ}$ for 1 hr and allowed to cool to room temperature. Crystallization of the resulting viscous oil was induced by grinding with fresh acetone. The filtered product was washed with acetone, ether and dried under vacuum at $60^{\circ}$ for 1 hr (yield $50 \mathrm{~g}$ ).

The product was purified by adding $12 \mathrm{~g}$ of the crude material to a stirred solution containing $200 \mathrm{~m} 1$ of absolute ethanol and $100 \mathrm{ml}$ of acetone, Filtering and discarding the undissolved material. Treatment of the filtrate with excess absolute ether resulted in a purple precipitate which was removed by filtration, washed with absolute ether and dried under vacuum at $60^{\circ}$ for $1 \mathrm{hr}$. This total yield $(8.1 \mathrm{~g})$ was dissolved in $100 \mathrm{ml}$ of boiling propanol, allowed to cool to room temperature, filtered and the resulting crystals discarded. The Eiltrate was maintained at $-18^{\circ}$ for $3 \mathrm{hr}$, filtered and the crystals washed with acetone and absolute ether. The pure violet product is very hygroscopic and was analyzed after drying at $110^{\circ}$ to constant weight (yield $1.2 \mathrm{~g}, 11.1 \%$ ). Anal. $\mathrm{Ca} 1 \mathrm{~cd}$ for $\left[\mathrm{Cr}(\mathrm{pn}){ }_{2} \mathrm{Cl}_{2}\right] \mathrm{Cl}: \mathrm{C}, 23.49 ; \mathrm{N}, 18.27 ; \mathrm{H}, 6.58 ; \mathrm{Cl}$, 34.75. Found: $\mathrm{C}, 23.29 ; \mathrm{N}, 18.10 ; \mathrm{H}, 6.64 ; \mathrm{Cl}, 34.57$. ais-[Cr(pn) $\left.{ }_{2} \mathrm{Br}_{2}\right] \mathrm{Br}$. This complex was prepared from the above ois-[Cr(pn) $\left.{ }_{2} \mathrm{Cl}_{2}\right] \mathrm{Cl}$ in a manner similar to that used for 
the ethylenediamine analog (6). The cis dichloro complex ( $1.2 \mathrm{~g})$ was dissolved in $5 \mathrm{ml}$ of $\mathrm{H}_{2} \mathrm{O}$ and maintained at $60^{\circ}$ for $20 \mathrm{~min}$. Then $4 \mathrm{ml}$ of $48 \% \mathrm{HBr}$ was added and the solution evaporated on a steam bath under a stream of $\mathrm{N}_{2}$. This was followed by another 4-m 1 addition of $H B r$ and the evaporation repeated as before. The moist product was dried by heating at $70^{\circ}$ under vacuum and washed with absolute ether. The crude product was then stirred with $130 \mathrm{ml}$ of acetone in the dark for $10 \mathrm{~min}$, filtered, the residue discarded and the product precipitated from the filtrate with excess absolute ether. After drying under vacuum at $60^{\circ}$ for $1 \mathrm{hr}$, the precipitate was treated with $100 \mathrm{ml}$ of boiling nitromethane, the residue discarded and the filtrate kept overnight at $-18^{\circ}$. The resulting dark violet crystals were washed with ether and dried under vacuum at $100^{\circ}$ for 2 hrs (yield 0.20 $\mathrm{g}, 12 \%)$. Anal. Calcd for $\left[\mathrm{Cr}(\mathrm{pn})_{2} \mathrm{Br}{ }_{2}\right] \mathrm{Br}: \mathrm{C}, 16.38 ; \mathrm{N}, 12.73$; $\mathrm{H}, 4.58 ; \mathrm{Br}, 54.48 ; \mathrm{Cr}, 11.82$. Found: $\mathrm{C}, 16.48 ; \mathrm{N}, 12.65 ; \mathrm{H}$, $4.51 ; \mathrm{Br}, 54.41 ; \mathrm{Cr}, 11.61$.

cis-[Cr(pn) $\left.{ }_{2}\left(\mathrm{OH}_{2}\right) \mathrm{Br}\right]^{2+}$. This cationic species was prepared in solution by dissolving $55 \mathrm{mg}$ of cis-[Cr(pn) $\left.{ }_{2} \mathrm{Br}_{2}\right] \mathrm{Br}$ in $50 \mathrm{ml}$ of $0.1 \mathrm{~N} \mathrm{HClO}_{4}$ and allowing the complex to aquate for 16 min at room temperature in the dark. The solution was then absorbed on a $40 \mathrm{~mm} \times 9 \mathrm{~mm}$ diameter jacketed column of Dowex AG50W-X8 cation exchange resin (100-200 mesh in the $\mathrm{H}^{+}$form). The column was kept at $0^{\circ}$ and protected from light with Al foil throughout the elution procedure. The unreacted cis dibromo was eluted with $1 \mathrm{~N} \mathrm{HClO}_{4^{\circ}}$. Additional $1 \mathrm{~N} \mathrm{HClO} 4_{4}$ was used to slowly move the desired eis bromoaqu band to the bottom of the 
column. It was then eluted with $50 \mathrm{ml}$ of $2.0 \mathrm{~N} \mathrm{HCl0} 4$, and the spectrum recorded. The $C r / B r$ atom ratio of this species is 1.01 and its elution behavior is very simflar to its en analog.

Bromide was determined in the above complexes by potentiometric titration (1) and chromium was measured spectrophotometrically as $\mathrm{CrO}_{4}{ }^{2-}$ after oxidation with alkaline peroxide (3). The dichloro complex was not analyzed for chromium because accurate welghings were precluded due to the hygroscopic nature of this salt. The remaining elements were determined by microanalysis.* The visible absorption spectra of the solid samples in $0.1 \mathrm{~N} \mathrm{HClO}_{4}$ or $\mathrm{HNO}_{3}$ at $0^{\circ}$ were recorded immediately after dissolution with a Cary Mode1 14 spectrophotometer.

\section{Discussion}

Some time ago Wendlandt and Sveum (7) described the preparation of cis complexes of the type $\left[\mathrm{Cr}(\mathrm{p} n)_{2} \mathrm{X}_{2}\right] \mathrm{X}$ by a thermal matrix method. This preparative procedure involves heating $\left[\mathrm{Cr}(\mathrm{pn})_{3}\right] \mathrm{x}_{3}$ and an excess of the corresponding ammonium halide at $160^{\circ}$ and $210^{\circ}$ ( $f \circ x=C l$ and $B$ respectively). These authors reportedly removed all impurities from the products by vacuum sublimation and characterized their products by elemental analysis and reflectance spectra. Numerous efforts to prepare analytically pure cis dibromo in our laboratory by this method always met with failure. In our hands unreacted tris complex and other impurities were always present at the end of the reported reaction and sublimation times. We found that treatment

\footnotetext{
* Microanalysis by M-H-W Microanalytical Laboratories, Garden City, Michigan.
} 
of the crude product with absolute alcohol, followed by ether precipitation of the filtrate and repeated recrystallization of the residue with nitromethane gave a material in small yield $(<1 \%)$ whose $\% \mathrm{Cr}$ was within the expected range. We abandoned this synthetic route when 1 t was recently demonstrated that the isomertc purity of some thermal matrix products of this type is questionable (5).

Esparza and Garner (8) attempted to prepare pure cis$\left[\mathrm{Cr}(\mathrm{pn})_{2} \mathrm{Cl}_{2}\right] \mathrm{ClO}_{4}$ in a manner similar to that used for the corresponding en analog but found two major disadvantages in their procedure. First, the product appeared always to contain several per cent $\mathrm{pn} \cdot 2 \mathrm{HClO}_{4}$. Secondly, the reaction mixture proved to be potentially hazardous and on one occasion detonated violently, seriously injuring one of the authors. Our non-aqueous procedure overcomes both of these problems.

We were able to confirm the configurations of the complexes reported here by thelr spectra and cation exchange characterist1cs. Table I shows no tetragonal splitting of the low energy bands of these cis complexes which is typical of the trans complexes of this type. The molar absorbancy indices of the cis dichloro complex are $-5 \%$ lower than those previously reForted (5). Since the elution behavior from $\mathrm{H}^{+}$Dowex AG50W-X8 resin is known for both trans dihalo species $(1,9)$, it was possible to check for isomeric purity of our cis dihalo products by fon exchange. No discernable trans dihalo contamination was found for either of these cis products by this technique. 
TABLE I

Visible Absorption Maxima and Minima of Cis-[Cr(AA) $2^{A X]^{n+}}$ Complexes in Acidic Aqueous Solution ${ }^{\dagger}$

\begin{tabular}{|c|c|c|c|c|c|c|}
\hline A. & $\mathrm{x}$ & $* \mathrm{AA}$ & $\max (n m)$ & $\min (\mathrm{nm})$ & $\max (n m)$ & Media \\
\hline$* \star C 1$ & $\mathrm{Cl}_{1}$ & en & $402(68.5)$ & $456(20.7)$ & $528(70.6)$ & $0.1 \mathrm{~N} H \mathrm{HC} 1$ \\
\hline$\S \subset 1$ & $\mathrm{Cl}$ & $\mathrm{pn}$ & $401(73.6)$ & $456(22.2)$ & $529(75.4)$ & $0.1 \mathrm{~N} \mathrm{HC10}$ \\
\hline$\star \S B r$ & $\mathrm{Br}$ & en & $415(83.0)$ & $468(29.2)$ & $544(89.4)$ & $0.1 \mathrm{~N} \mathrm{HC10} 4$ \\
\hline$\S \mathrm{B} \mathrm{I}$ & $\mathrm{Br}$ & $\mathrm{pn}$ & $410(79.8)$ & $463(27.4)$ & $537(85.6)$ & $0.1 \mathrm{~N} \mathrm{HNO}{ }_{3}$ \\
\hline$\star \S B r$ & $\mathrm{H}_{2} \mathrm{O}$ & en & $387(60.5)$ & $446(21.0)$ & $519(72.2)$ & $0.04 \mathrm{~N} \mathrm{HNO}_{3}$ \\
\hline$\S \mathrm{Br}$ & $\mathrm{H}_{2} \mathrm{O}$ & $\mathrm{pn}$ & $390(62.9)$ & $443(22.4)$ & $51.8(75.6)$ & $2.0 \mathrm{~N} \mathrm{HClO}_{4}$ \\
\hline
\end{tabular}

tValues inside parentheses are the molar absorbancy indices

(extinction coefficients) in $\mathrm{M}^{-1} \mathrm{~cm}^{-1}$.

*A11 en spectra at $25^{\circ}$ and pn spectra at $0^{\circ} . \quad * *$ Ref. 10.

$\S$ This research. *ईRef. 6 .

\section{References}

1. J. A. MCLEAN, JR. and R. I. GOORMAN, Inorg. Nucl. Chem. Letters, 7 , 9 (1971).

2. J. GLERUP, J. JOSEPHSEN, K. MICHELSEN, E. PEDERSEN and C. E. SCHAFFER, Acta. Chem. Scand., 24, 247 (1970).

3. J. A. MCLEAN, JR. and R. R. BARONA, Inorg. Nucl. Chem. Letters, $\underline{5}, 385$ (1969).

4. J. W. VAUGHN and B. J. KRAINC, Inorg. Chem., 4, 1077 (1965).

5. E. PEDERSEN, Acta. Chem. Scand, 24, 3362 (1970).

6. L. P. QUINN and C. S. GARNER, Inorg. Chem., 3, 1348 (1964).

7. W. W. WENDLANDT and L. K. SVEUM, J. Inorg. Nucl. Chem., 29, 975 (1967).

8. M. ESPARZA and C. S. GARNER, J. Inorg. Nucl. Chem., 29, 2377 (1967).

9. R. R. BARONA and J. A. MCLEAN, JR., Inorg. Chem., 10,286 $(1971)$.

10. D. J. MACDONALD and C. S. GARNER, J.Am. Chem. Soc., 83, 4152 (1961). 